\title{
COMPUTER AIDED TOOL SUPPORT (CATS) FOR INFORMATION STRATEGY PLANNING (ISP): GENERATING APPLICATION PORTFOLIO FOR BUSINESS AREA ANALYSIS
}

\author{
Juliana Wahid ${ }^{1}$, Zulkhairi Md Dahalin², Mohd Rushdi Idrus³, Mohd Adan \\ $\mathrm{Omar}^{4}$
}

College of Arts and Sciences
Universiti Utara Malaysia

w.juliana@uum.edu.my ${ }^{l}$

zul@uum.edu.my²

rushdi@uum.edu.my

adan@uum.edu.my

\begin{abstract}
Information Strategy Planning (ISP) is concerned with an organization's plan to acquire appropriate "IT blueprint" encompassing suitable hardware, software and telecommunication facilities for the utilization of applications required by the business with adequate support structure. The purpose is to determine the enterprise's business goals and a high-level overview of the enterprise, its functions, data and information needs. This research builds an ISP engine, i.e. the Computer Aided Tool Support (CATS) that has the capability to generate application portfolios that can support the business strategy of the enterprise. Application portfolio is a major part of the ISP deliverables which can significantly aid in formulating suitable strategies for IT supply and IT support structure. CATS will help to facilitate End-User Computing as a tool not only to ease endusers in planning for their IT adoption, but also to ensure that their IT investment is aligned to business goals and strategies. CATS will be able to help the Small Medium Enterprise (SME) companies and other organizations in their information-systems planning so that they can achieve their missions and objectives in a more efficient way.
\end{abstract}

Keywords: Information Strategic Planning (ISP), Computer Aided Tool Support (CATS), Application Portfolio, Small Medium Enterprise (SME). 


\section{INTRODUCTION}

Realizing the importance of an ISP for the organization, top management should consider conducting an ISP in order to ensure that its IT investment supports the organization's business requirements and strategies. This paper describes the development of a web-based prototype tool that can model the information requirements of the enterprise and support its business mission, goals, and strategies.

Deliverables of ISP would include a suite of application portfolio and potential business areas, formation of corporate databases, the technical environment including hardware, software and networking, and organization of the enterprise's information systems.

This study intends to assist Small Medium Enterprises (SMEs) in their planning for IT adoption. The alignment between business and IT strategies contributes to the improvement in organizational performance (Motjolopane $\&$ Brown, 2004). However, without proper ISP, the organizations will face difficulties in ensuring adequate returns in their IT investment. During two research projects to identify the difficulties associated with informationsystems planning (ISP), it become apparent that managers and users often do not apply a number of commonly accepted guidelines for successful ISP such as (i) align with the organization's strategic plan, (ii) provide for an IT architecture that enables users, application and databases to be seamlessly networked and integrated and (iii) efficiently allocate IS development resources among competing projects so the projects can be completed on time, within the budget and have the required functionality (Lederer \& Medelow, 1989). On the other hand, to carry out an ISP study would require a high cost to be borne by the organization. Furthermore, for a small medium industry, due to its size and financial capabilities, managers do not have the time and resources to implement a complete ISP. To facilitate the process, several Computer Aided Software Engineering (CASE) tools in the marketplace can be used to automate the ISP process, thereby reducing the time taken to complete the ISP. However, these tools are extremely expensive and would require consultants that are not within the means of SMEs.

In order to address the above-mentioned problems, a prototype tool support that model the information and process requirements of the enterprise has been developed. The prototype tool was applied in selected cases to generate application portfolios. 


\section{LITERATURE REVIEW}

Information Strategic Planning (ISP) has been described as a system comprised of inputs, processing and outputs (Ang, Shaw \& Pavri, 1995), (King, 1988) and the purpose of ISP is to create a plan of recommendations that fulfil management objectives and thus benefit the organization (Raghunathan \& Raghunathan, 1994), (Segars, 1994). It also includes the specification of databases and systems to support those applications (Hartono, Lederer, Sethi, \& Zhuang, 2003).

According to Blumenthal (1969) the need for ISP was recognized as early as 1969 and the benefits of formalized ISP have been documented. Planning involves setting objectives and policies to enable an organization or department to deploy its resources effectively and efficiently to achieve its goals (Drucker, 1979). Drucker (1979) also said that the act of planning requires making risktaking decisions at the present time with the best possible knowledge of their outcomes. Clearly, without planning it is very difficult to achieve anything at all. Cash, Macfarlan and McKenney (1988) found that ISP offers informationintensive industries greater opportunity for strategic benefits.

An application portfolio is a very important aspect to manage in an organization to meet management goals and strategies for customers, and shareholders, value (Weill, \& Broadbent, 1998). Application portfolio models provide the means for balancing the portfolio and the life cycle of the information systems. They also provide the management approaches to meet the goals of the enterprise and to create the maximum benefit.

Using ISP, the process of identifying a portfolio of computer-based applications that will assist an organization in executing its business plans and realizing its business goals can be done (Hartono, Lederer, Sethi, \& Zhuang, 2003).

To ease the ISP process, several CASE tools have been introduced by several vendors such as AllFusion:Gen (formerly known as COOL:Gen) by Computer Associates International, Inc. (CA) and Application Development Workbench (ADW) by KnowledgeWare. AllFusion:Gen provides a proven development environment for designing, deploying and maintaining a high-performance enterprise application. Using AllFusion:Gen developers can rapidly produce complex e-Business applications that meet changing requirements (CA, 2007). ADW is a large tool set for information engineering. ADW tools are grouped according to Information Engineering (IE) stages into for subsets called workstations: planning workstation, analysis workstation, design workstation and construction workstation (KnowledgeWare Inc., 1994). However, these tools are extremely expensive and would require consultants to use them. 
This study introduces a web-based Computer Aided Tool Support (CATS) that can generate application portfolios applicable to SMEs. As Zulkhairi (2005) discussed that there are two ways in generating application portfolios i.e. best guess and cluster analysis, this tool is developed using the cluster analysis. According to Zulkhairi (2005), the technique of best guess groups the entity types together according to the processes and functions to generate the application portfolio while cluster analysis uses affinity algorithm in generating the application portfolio. Affinity algorithm has been used in various applications for metric clustering purposes. Liu, Zhang, Chen, Lyu and Ma (2004) used affinity ranks to improve information-retrieval performance based on two proposed evaluation metrics; diversity and information richness. Zhang, Li, Liu, Ji, Fan, Chen \& Ma (2005) proposed affinity rank to re-rank search results by optimizing two metrics (diversity and information richness) to improve web-search results. For this study affinity algorithm is used to optimize two metrics which are functional model and data model.

\section{DEVELOPMENT}

The CATS prototype was developed on a web-based environment using Active Server Page (ASP) 3.0 as the development environment and Microsoft Access as the database that forms the repository to capture the data and process models. The idea of a web-based platform is to facilitate group work and ease of communicating the requirements and models generated by the prototype to members of the workgroup or users.

The core of the design is building up of the affinity analysis engine. Since this is a prototype system, the design of the user-interface will be simplified. However, the logic of the affinity analysis algorithm is complete. Figures 1 through 4 show the systems architecture of the CATS for ISP. Each user representing an organization will be assigned a separate user account to build their enterprise information model separately. Two main components of the architecture in which the user can access are the Organization Chart planning object and the Subject Area planning object as in Figures 2 and 3. The Organization Chart planning object forms the basis for the Business Function and Process model, whilst the Subject Area planning object will be used to create entities that are of interest to the organization. Users will be most familiar with their own organization structure, therefore providing them with the facility to model their business based on the organization chart would produce an accurate business function and process model. After the user has entered the information regarding the organization structure and the subject area that is of interest to the organization, the prototype will then transform 
this information into a first-cut initial functional model, and a data (entity) model, respectively. This is also known as the Initial Enterprise Information Model, which is the first phase of the prototype function. To aid the user with the initial models, baseline functions and subject areas are supplied that represent typical business functions and information requirements. The user may choose to select the objects appropriate for the business and may also drop objects not relevant to the business.

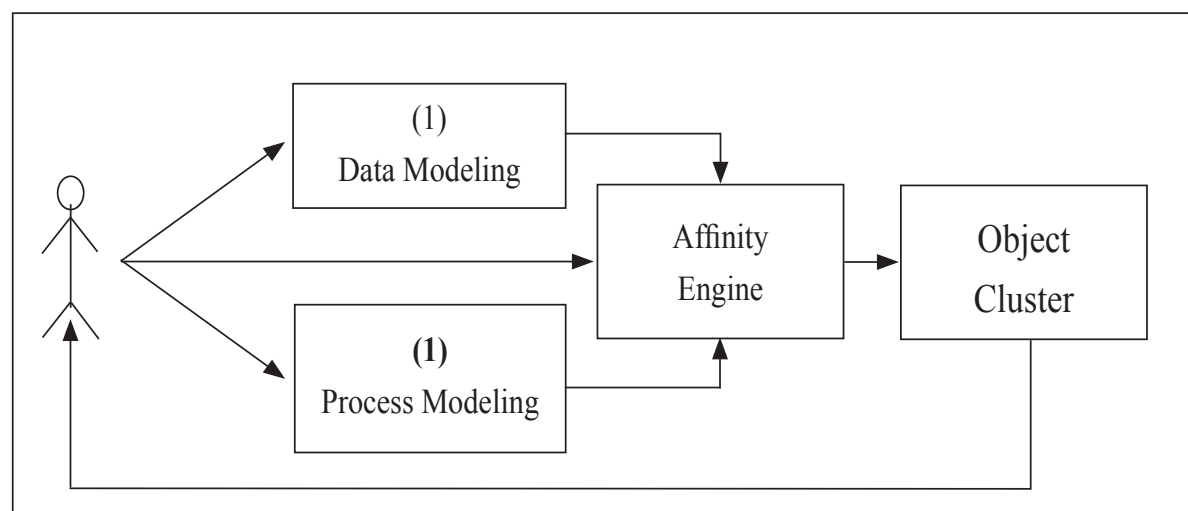

Figure 1. Basic System Architecture

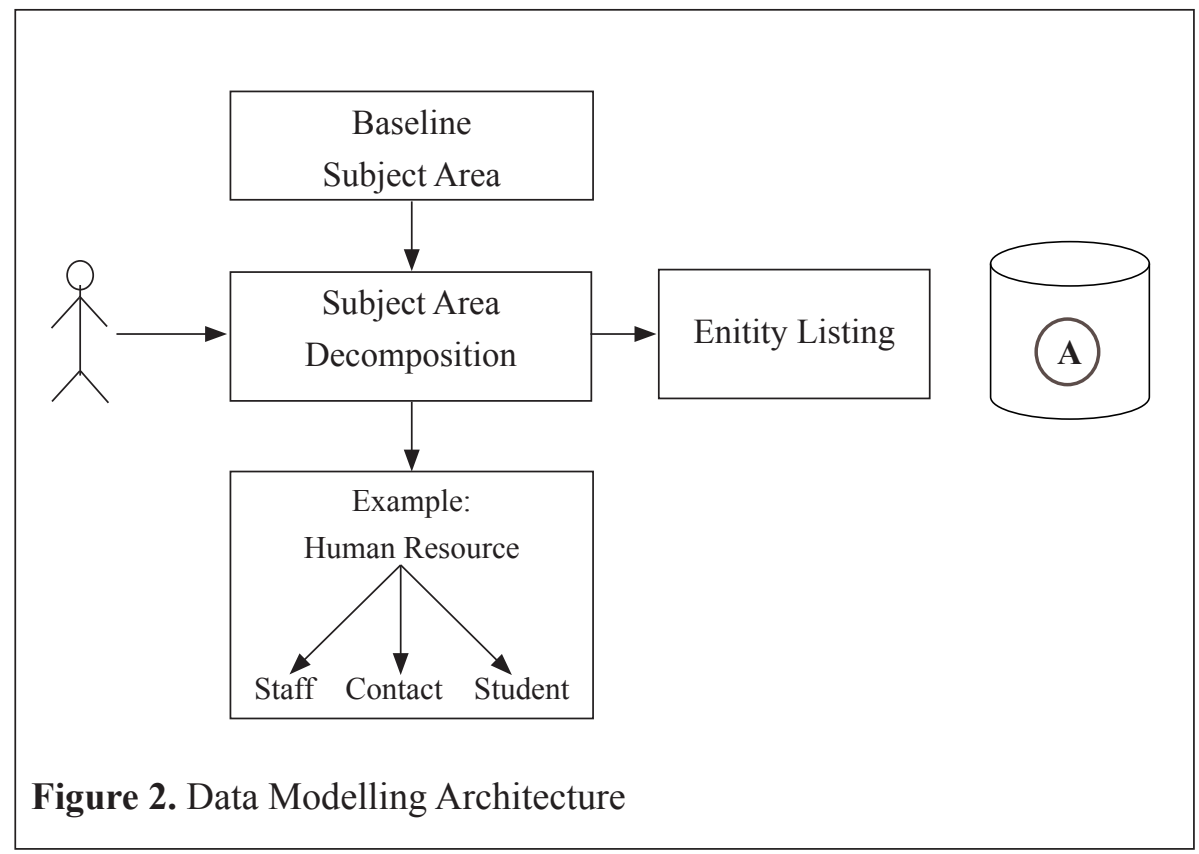




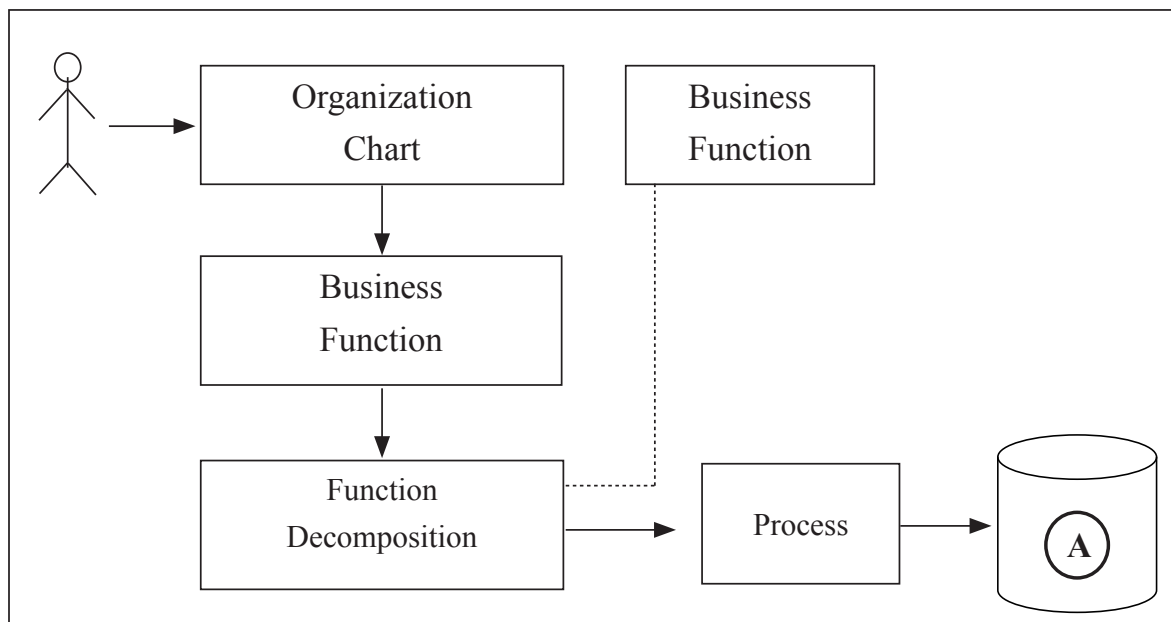

Figure 3. Process Modelling Architecture

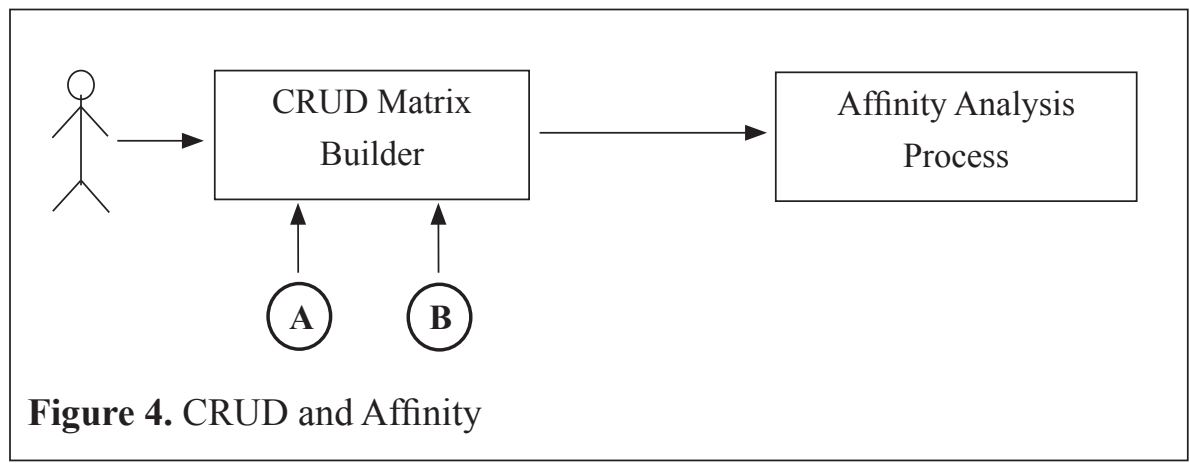

The second phase of the prototype function involve the creation of the Refined Enterprise Information Model. The initial functional and data models will then be accessed by the user(s) to refine them further into sufficient level of details. To achieve this, the prototype provides a hierarchical representation of the information where the user can break down information into finer details. This can be an iterative process, where users can store and retrieve the model repeatedly, go through with other users until they are satisfied with the accuracy of the model representing the organization's requirements. The final version of the model will then become the refined enterprise information model, ready to be analysed in the next phase.

The third phase of the prototype function is to make an analysis of the relationship between a given business function or process and a corresponding 
entity. The idea is to examine the type of business operation that a given function or process is capable of acting upon on a particular entity or piece of information. An activity (function or process) can act upon a data (entity) in one or combinations of four operations: Create, Read, Update, and/or Delete. Thus a matrix known as the CRUD (short form for Create, Read, Update, Delete) will be generated by the prototype associating the list of business functions (or processes) with the list of entities supplied by the users in the first two phases as shown in Figure 4. This will be a highly interactive session whereby the users will be examining every piece of information relating a particular business function (or process) to its corresponding entity. For every pair of function-entity association, the user will have to base it on business sense to make up the operation that can be acted upon for that particular function to its corresponding entity pair. For example, the function Recruit Personnel and the entity Staff will have the operation Create associated with them since in Recruit Personnel a major activity is to hire new staff and create a record of the new staff in the organization's database. Therefore, the user will interact with the CRUD matrix by entering " $\mathrm{C}$ " (or clicking the value " $\mathrm{C}$ " in the pull down menu) in the cell that forms the intersection between Recruit Staff and Staff in this example. The operation is repeated for all functionentity pair, skipping those pairs that make no business sense to be associated by leaving to those cells blank.

The fourth and final phase of the prototype function involves very minimal user intervention but is a highly intensified, number-crunching computerization involving complex and sophisticated algorithm. This is the Affinity Analysis engine. In this study development of the Affinity Analysis engine is based on the principle of Cluster Analysis. This technique is based on the same CRUD Matrix as mentioned before, but using certain mathematical formulas to cluster closely-coupled entities based on their associations with the corresponding functions (or processes). Again, as in the previous example, the "C" in each cell of the CRUD matrix is used to determine whether a common relationship exists between the entities being created by a function or process. A relationship between a function and an entity exists if the process uses (or creates) the entity in its execution. These relationships are recorded in the cells of the CRUD matrix mentioned earlier. The common relationship between the entities is determined by using factor analysis based on pair-wise comparison between the entities. Factor analysis is a tedious process involving a large number of calculations, particularly when deciding whether an entity should belong to an existing cluster as this will involve calculations of weighted average to determine the degree of "closeness" of the entity to the existing cluster. For this reason, an Entity Clustering Algorithm is built to automate the affinity analysis process which forms the core of the Affinity Analysis engine. 
The algorithm computes Affinity Factors, which represent the proportion of the number of functions using a pair of entities out of the number of functions using one element of the pair. For example let $\mathrm{E}_{1}, \mathrm{E}_{2}, \mathrm{E}_{3}, \ldots . ., \mathrm{E}_{\mathrm{m}}$ be the entities and $\mathrm{F}_{1}, \mathrm{~F}_{2}, \mathrm{~F}_{3}, \ldots \ldots, \mathrm{F}_{\mathrm{n}}$ be the functions in the M-by-N matrix. The Entity Clustering algorithm can examine every function and calculate (a) the number of functions using a given entity $\mathrm{E}_{1}$, say, (b) the number of functions using the entity pair $\mathrm{E}_{1}$ and $\mathrm{E}_{\mathrm{k}}$ where $\mathrm{k}$ is between 1 and $\mathrm{m}$ inclusive and $\mathrm{k} \neq 1$. Hence, let:

$\mathrm{F}\left(\mathrm{E}_{1}\right)=$ number of functions using $\mathrm{E}_{1}$ $F\left(E_{1}, E_{k}\right)=$ number of functions using both entities $E_{1}$ and $E_{k}$ The Affinity Factor $E_{1}$ to $E_{k}=\underline{F\left(E_{1}, E_{k}\right)}$

$$
\mathrm{F}\left(\mathrm{E}_{1}\right)
$$

The Entity Factor E1 to $\mathrm{E}_{\mathrm{k}}$ is a percentage value that measures the degree of correlation or "similarity" between the two entity types with the aim of making a decision whether to cluster the entity pair together or not. It makes sense that commonly referred entity types by the same function(s) should be clustered together to form logical business areas. An Affinity Factor of 100\% or approaching $100 \%$ would tend to cluster the entity types together, whereas Affinity Factors with low percentage values would separate the entity types into different clusters and business areas.

The algorithm incorporated in the Affinity Analysis engine will calculate the affinity factors of all entity pairs and generate a new Affinity Matrix that stores the affinity factors computed earlier. The next step in the Affinity Analysis is to perform the entity clustering. Entities with high affinity factors will be grouped together to form an entity cluster. This is accomplished by sorting those pairs of entities that have the highest affinity factor and conducting a test cycle to determine whether the pair can be grouped together to form a cluster.

For each cycle the algorithm will select the maximum remaining affinity between a pair of entities and check whether either entity has been assigned to an existing group or cluster. If both entities were unassigned, then a new group or cluster will be created and both entities will be assigned to that group. On the other hand, if both entities have been assigned, then nothing happens. No new group is created, neither assigned to an existing group. However, if either one of the entities has already been assigned to an existing group, or the other entity has not been assigned, then the algorithm needs to determine whether the unassigned entity can be added to the existing group. This is done by calculating the "weighted affinity" based on the weighted average of the 
unassigned entity to the existing entities in the group or cluster. The following illustration describes the formula used to compute the weighted affinity of an entity E3 to a cluster consisting of two other entities, E1 and E2.

Say E1, E2 are assigned to Group 1, and to calculate the weighted affinity E3 say, to cluster E1, E2, i.e.

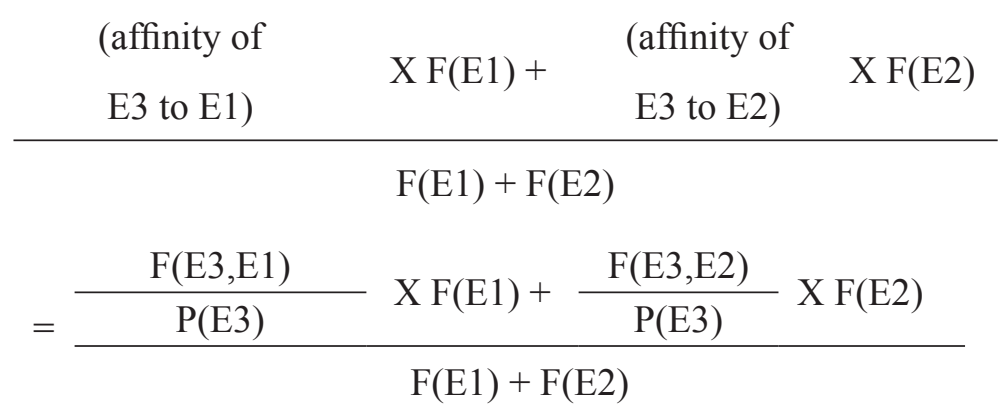

is the value for the weighted affinity factor.

If the weighted affinity E3 to cluster E1, E2 is higher than any remaining affinity number, then E3 will be included in the cluster forming E1, E2, E3.

Results of the entity clustering are generated by the Affinity Analysis engine in the form of an Affinity Analysis Report. This report will be further analysed by the user to examine the most appropriate label to represent the cluster of entities. A cluster or combination of clusters can form a potential business area that makes business sense to the enterprise. The prototype will prompt the user to enter the business area classifications representing the IS applications for each entity cluster generated by the engine. These IS applications will be used by the enterprise to justify its IT investment in acquiring the most appropriate IT solutions that meet its business strategy and requirements.

\section{ANALYSIS OF CASE STUDY}

In both the cases conducted (known as Company A, and Company B), the owners of the companies themselves were involved in testing the prototype. A questionnaire which was used as the test instrument was completed by the owners after using the prototype. The questionnaire was based on four categories, namely, the System Usability, Perceived Usefulness, Ease of Use and After Scenario. Figure 5 shows the average results of the test according to the four categories. 
Questionnaire Result from All Participants

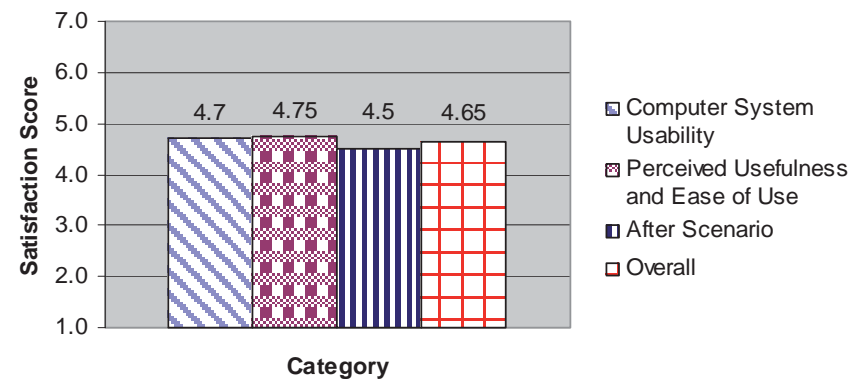

Figure 5. Questionnaire Results

For the computer system usability category, the average score was 4.7, while for the perceived usefulness and ease of use category, the score was 4.75. The after scenario category recorded a 4.5 score. Overall, the average score was 4.65. From this score, we can say the acceptance is above average.

In addition to the prototype usability, the prototype outputs from the testing were also captured such as business function versus entity matrix, computed affinity between entities matrix, affinity analysis report and grouping of entities according to application portfolio. These outputs were then verified by the owners as to whether they suit the information system enterprises' needs. Below are the details of the analyses of the prototype output for both companies.

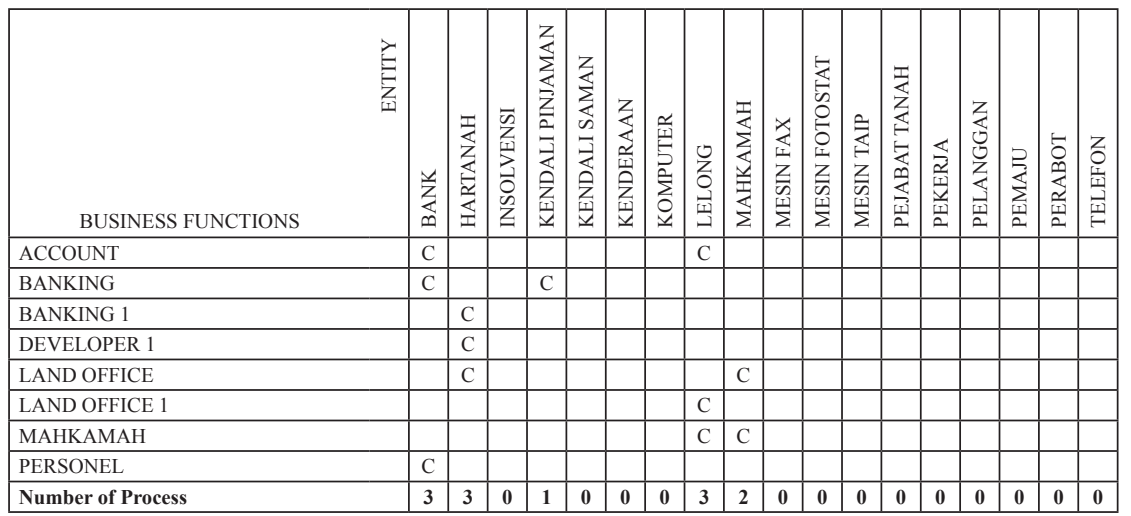

Figure 6. Matrix of Business Function/Entity for Company A 
The relationship between 8 business functions and 18 entities of company A produces 12 processes of CREATE (C) as shown in Figure 6. The calculation of the affinity factors of all the entity pairs generates the Affinity Matrix as shown in Figure 7. Affinity factor represents the strongest of relationship between two entities.

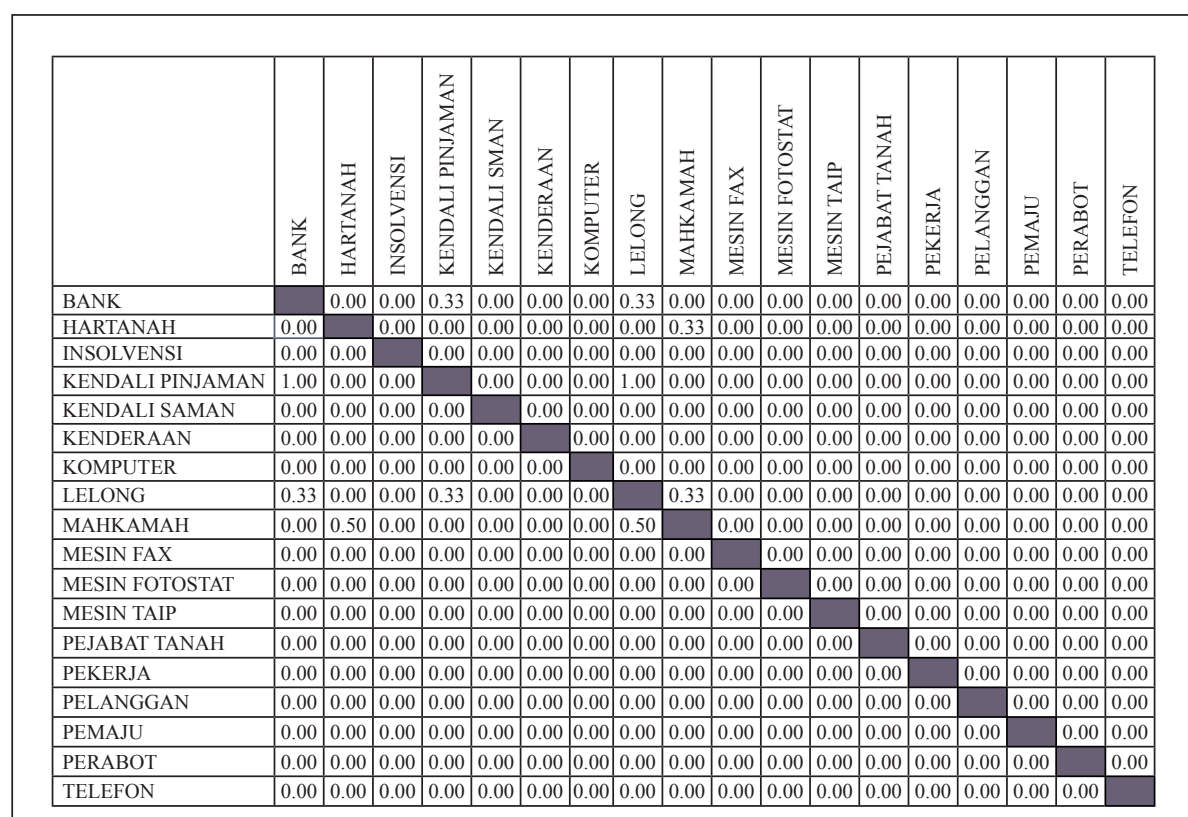

Figure 7. Matrix of Computed Affinity Between Entities for Company A

The analysis of CRUD produces 4 cycles with 2 values of affinity factor which are 1.0 and 0.5 . The affinity factor value of 1.0 is for bank (E1) with kendali pinjaman (E2) and lelong (E1) with kendali pinjaman (E2). The affinity factor value of 0.5 is for hartanah (E1) with mahkamah (E2) and lelong (E1) with mahkamah (E2) as shown in Figure 8.

\begin{tabular}{|c|l|l|c|}
\hline Cycle \# & Entity 1 & \multicolumn{1}{|c|}{ Entity 2 } & Affinity Factor \\
\hline 1 & BANK & KENDALI PINJAMAN & 1.00 \\
\hline 2 & LELONG & KENDALI PINJAMAN & 1.00 \\
\hline 3 & HARTANAH & MAHKAMAH & 0.50 \\
\hline 4 & LELONG & MAHKAMAH & 0.50 \\
\hline
\end{tabular}

Figure 8. Report of Affinity Analysis for Company A 
The end result as shown in Figure 9 produces two business area classifications representing the Application Portfolio, which the users themselves classified as the litigation system for the entity group bank, kendali pinjaman (manage loans) and lelong (auction). While for the second business area classification the users classified it as the conveyancing system for the entity group hartanah (real estate) and mahkamah (court). This result shows that company A needs two types of information systems litigation and conveyancing system, as most of the work done by the company involves these two related works.

\begin{tabular}{|c|l|l|}
\hline Group \# & Business Area Classification & \multicolumn{1}{|c|}{ Entity Types in Group } \\
\hline 1 & LTIGATION SYSTEM & BANK, KENDALI PINJAMAN, LELONG \\
\hline 2 & CONVEYANCING SYSTEM & HARTANAH, MAHKAMAH \\
\hline & SAVE & \\
\hline
\end{tabular}

Figure 9. Application Portfolio for Company A

In organization $\mathrm{B}$, the relationship between 11 entities and 8 business functions produces 18 processes of CREATE (C) as shown in Figure 10. The affinity factor of all the entity pairs is shown in Figure 11.

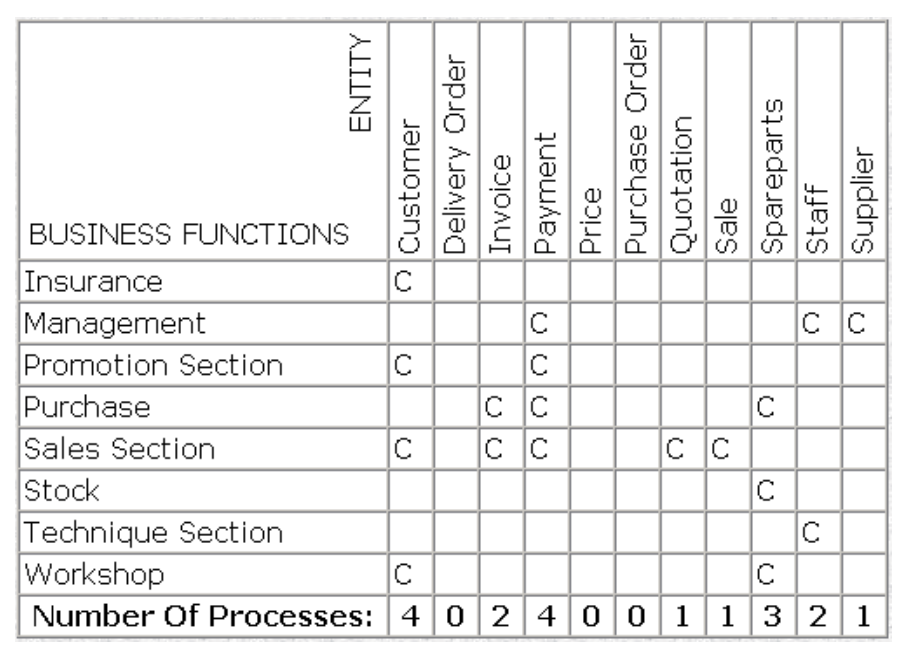

Figure 10. Matrix of Business Function/Entity for Company B 


\begin{tabular}{|c|c|c|c|c|c|c|c|c|c|c|c|}
\hline & 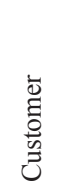 & 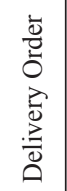 & $\begin{array}{l}\stackrel{\circlearrowright}{0} \\
\stackrel{0}{\Xi} \\
.\end{array}$ & 芯 & $\stackrel{\circlearrowright}{=}$ & 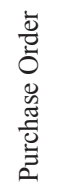 & 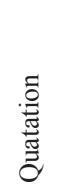 & $\frac{0}{\pi}$ & 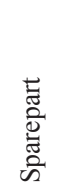 & 恋 & 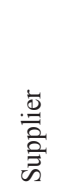 \\
\hline Customer & & 0.00 & 0.25 & 0.50 & 0.00 & 0.00 & 0.25 & 0.25 & 0.25 & 0.00 & 0.00 \\
\hline Delivery Order & 0.00 & & 0.00 & 0.00 & 0.00 & 0.00 & 0.00 & 0.00 & 0.00 & 0.00 & 0.00 \\
\hline Invoice & 0.50 & 0.00 & & 1.00 & 0.00 & 0.00 & 0.50 & 0.50 & 0.50 & 0.00 & 0.00 \\
\hline Payment & 0.50 & 0.00 & 0.50 & & 0.00 & 0.00 & 0.25 & 0.25 & 0.25 & 0.25 & 0.25 \\
\hline Price & 0.00 & 0.00 & 0.00 & 0.00 & & 0.00 & 0.00 & 0.00 & 0.00 & 0.00 & 0.00 \\
\hline Purchase Order & 0.00 & 0.00 & 0.00 & 0.00 & 0.00 & & 0.00 & 0.00 & 0.00 & 0.00 & 0.00 \\
\hline Quatation & 1.00 & 0.00 & 1.00 & 1.00 & 0.00 & 0.00 & & 1.00 & 0.00 & 0.00 & 0.00 \\
\hline Sale & 1.00 & 0.00 & 1.00 & 1.00 & 0.00 & 0.00 & 1.00 & & 0.00 & 0.00 & 0.00 \\
\hline Sparepart & 0.33 & 0.00 & 0.33 & 0.33 & 0.00 & 0.00 & 0.00 & 0.00 & & 0.00 & 0.00 \\
\hline Staff & 0.00 & 0.00 & 0.00 & 0.50 & 0.00 & 0.00 & 0.00 & 0.00 & 0.00 & & 0.50 \\
\hline Supplier & 0.00 & 0.00 & 0.00 & 1.00 & 0.00 & 0.00 & 0.00 & 0.00 & 0.00 & 1.00 & \\
\hline
\end{tabular}

Figure 11. Matrix of Computed Affinity Between Entities for Company B

Twenty cycles are generated for E1 and E2 with an affinity factor range of 1.0 and 0.5 as shown in Figure 12.

\begin{tabular}{|c|l|l|c|}
\hline Cycle \# & \multicolumn{1}{|c|}{ Entity 1 } & \multicolumn{1}{|c|}{ Entity 2 } & Affinity Factor \\
\hline 1 & Customer & Quatation & 1.00 \\
\hline 2 & Customer & Sale & 1.00 \\
\hline 3 & Invoice & Quatation & 1.00 \\
\hline 4 & Invoice & Sale & 1.00 \\
\hline 5 & Payment & Invoice & 1.00 \\
\hline 6 & Payment & Quatation & 1.00 \\
\hline 7 & Payment & Sale & 1.00 \\
\hline 8 & Payment & Supplier & 1.00 \\
\hline 9 & Quatation & Sale & 1.00 \\
\hline 10 & Sale & Quatation & 1.00 \\
\hline 11 & Staff & Supplier & 1.00 \\
\hline 12 & Customer & Invoice & 0.50 \\
\hline 13 & Customer & Payment & 0.50 \\
\hline 14 & Invoice & Payment & 0.50 \\
\hline 15 & Payment & Customer & 0.50 \\
\hline 16 & Payment & Staff & 0.50 \\
\hline 17 & Quatation & Invoice & 0.50 \\
\hline 18 & Sale & Invoice & 0.50 \\
\hline 19 & Sparepart & Invoice & 0.50 \\
\hline 20 & Supplier & Staff & 0.50 \\
\hline
\end{tabular}

Figure 12. Report of Affinity Analysis for Company B

The end result as shown in Figure 13 is only one business area classifications for the group entity of customer, quotation, sale, invoice, payment, supplier, staff and spare part. The result of this application portfolio for company B requires one type of information system for its daily activities. 


\begin{tabular}{|c|c|c|}
\hline Group & Business Area Classification & \multicolumn{2}{c|}{ Entity Types in Group } \\
\hline 1 & Customer_Suppler__Staff Syystem & Customer, Quotation, Sale, Invoice, Payment, Supplier, Staff, Spareparts \\
\hline & SANE & \\
\hline
\end{tabular}

Figure 13. Application Portfolio for Company B

From these two case studies, it is interesting to note that for company B, there was a clear difference in its business area classification as compared to company A. Company B only has one business area classification. This could be due to two factors. The first factor was that it happened because of the high level of data entered and the second factor was because the number of business functions entered was relatively small.

\section{CONCLUSION}

The CATS is a web-based application that has user-friendly interface in helping end users without prior knowledge of ISP in mapping out their organization department, entities and business functions in a short period of time compared to the manual way. The usability test in the case study companies, successfully describes the development of prototype and applicability. The system is a solution for small and medium firms in helping them to implement ISP. Even government agencies can use CATS to assist in their ISP projects as required by the Manpower and Modernization Planning Unit (MAMPU).

However, this tool has several limitations such as the interface for CRUD analysis in the system should be upgraded to reflect its user-friendliness depending on the number of entities and business functions entered. Users need to scroll up and down and left to right frequently if the amount of data is large. The output does not display organization lining as what is displayed on the computer screen.

\section{FUTURE WORKS}

From the above-mentioned limitations, there are number of aspects that future work can look into: 
1. Researchers should continue with the prototype development until the full version that can generate an ISP for a company is completed.

2. The affinity algorithm and best guess is proven to be relevant in doing analysis for the information retrieval process. Further research needs to be done to test how these two methods can be further applied to get better consistency in the results.

\section{REFERENCES}

Ang, J., Shaw, N., \& Pavri, F. (1995). Identifying strategic management information systems planning parameters using case studies. International Journal of Information Management, 15(6), 463-474.

Blumenthal, S. C. (1969). Management information systems: A framework for planning and development. Englewood Cliffs. N. J.: Prentice Hall.

CA. (2007). Allfusion gen deployment environment. Retrieved from www3. ca.com

Cash, J. L., Macfarlan, F., \& McKenney, J. L. (1988). Corporate information system management. Irwin, Homewood.

Drucker, P. F. (1979). Technology, management and society. Harper and Row: New York.

Hartono, E., Lederer, A. L., Sethi, V., \& Zhuang, Y. (2003). Key predictors of the implementation of strategic information systems plans. The DATA BASE for Advances in Information Systems - Summer 2003, 34(3).

King, W. R. (1988). How effective is your information systems planning? Long Range Planning, 21(5), 103-112.

KnowledgeWare Inc. (1994). Application development workbench-overview, 0194-PU-0665. KnowledgeWare Inc. Atlanta.

Lederer, A. L. \& Mendelow, A. L. (1989). Information systems planning: Incentives for effective action. ACM SIGMIS Database, 20(3), 13-20 ACM Press.

Liu, Y., Zhang, B., Chen, Z., Lyu, M. R., \& Ma, W. (2004). Affinity rank: A new scheme for efficient web search. ACM. 
Motjolopane, I. \& Brown, I. (2004). Strategies business-IT alignment, and factors of influences: A case study in a public tertiary education institution. Proceeding of SAICSIT 2004, 147-156.

Raghunathan, T. S., \& Raghunathan, B. (1994). Adaption of a planning system success model to information system planning. Information Systems Research, 5(3), 326-340.

Segars, A. H. (1994). Strategic information system planning: The coalignment of planning system design, its relationship with organization context and implications for planning system success (Unpublished doctoral dissertation). University of South Carolina.

Weill, P., \& Broadbent, M. (1998). Leveraging the new infrasture: How market leaders capitalize in information technology. Harvard Business School Press.

Zhang, B., Li, H., Liu, Y., Ji, L. Xi, W. Fan, W., Chen, Z., \& Ma, W. (2005). Improving web search results using affinity graph. ACM.

Zulkhairi, M. D. (2005). Implementing information strategy planning in an enterprise. Sintok: Penerbit UUM. 